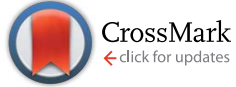

Cite this: RSC Adv., 2016, 6, 109234

Received 7th September 2016 Accepted 8th November 2016

DOI: 10.1039/c6ra22391e

www.rsc.org/advances

\section{The effect of oxygen vacancies on water wettability of transition metal based $\mathrm{SrTiO}_{3}$ and rare-earth based $\mathrm{Lu}_{2} \mathrm{O}_{3} \dagger$}

\author{
Tarapada Sarkar, $\neq^{\mathrm{a}}$ Siddhartha Ghosh, $\dot{t}^{\mathrm{a}}$ Meenakshi Annamalai, ${ }^{\mathrm{a}}$ Abhijeet Patra, ${ }^{\text {ac }}$ \\ Kelsey Stoerzinger, ${ }^{d}$ Yueh-Lin Lee, ${ }^{d}$ Saurav Prakash, ${ }^{a}$ Mallikarjuna Rao Motapothula, ${ }^{a}$ \\ Yang Shao-Horn, *d Livia Giordano*de and T. Venkatesan*abcfg
}

\begin{abstract}
Understanding the structural, physical and chemical properties of the surface and interfaces of different metal-oxides and their possible applications in photo-catalysis and biology is a very important emerging research field. Motivated in this direction, this article would enable understanding of how different fluids, particularly water, interact with oxide surfaces. We have studied the water contact angle of $3 \mathrm{~d}$ transition metal oxide thin films of $\mathrm{SrTiO}_{3}$, and of $4 \mathrm{f}$ rare-earth oxide thin films of $\mathrm{Lu}_{2} \mathrm{O}_{3}$. These metal oxides were grown using pulsed laser deposition and they are atomically flat and with known orientation and explicitly characterized for their structure and composition. Further study was done on the effects of oxygen vacancies on the water contact angle of the $3 d$ and $4 f$ oxides. For $3 d \mathrm{SrTiO}_{3}$ oxide with oxygen vacancies, we have observed an increase in hydroxylation with consequent increase of wettability which is in line with the previous reports whereas an interesting opposite trend was seen in the case of rareearth $\mathrm{Lu}_{2} \mathrm{O}_{3}$ oxide. Density functional theory simulations of water interaction on the above mentioned systems have also been presented to further substantiate our experimental findings.
\end{abstract}

\section{Introduction}

Metal oxides comprise a diverse class of materials with intriguing properties and vital technological utility. Controlling and/or altering the interface between liquid ('water' specifically) and metal oxide surfaces, which is termed as "wetting", is of immense scientific interest. Understanding the underlying phenomena of wetting at the molecular level in such material systems is crucial for numerous technological processes. Among these metal oxides, reversible tunability of water wetting has been extensively studied in systems such as $\mathrm{TiO}_{2}$ (ref. 1) and $\mathrm{ZnO}^{2-5}$ Reversible wettability

${ }^{a}$ NUSNNI-NanoCore, National University of Singapore (NUS), Singapore. E-mail: venky@nus.edu.sg

${ }^{b}$ Department of Electrical Engineering, National University of Singapore (NUS), Singapore

'NUS Graduate School for Integrative Sciences and Engineering, National University of Singapore (NUS), Singapore

${ }^{d}$ Electrochemical Energy Laboratory, Massachusetts Institute of Technology, Cambridge, USA.E-mail: lgiordan@mit.edu; shaohorn@mit.edu

${ }^{e}$ Department of Material Science, University of Milano-Bicocca, Milano, Italy

${ }^{f}$ Department of Materials Science and Engineering, National University of Singapore (NUS), Singapore

${ }^{g}$ Department of Physics, Faculty of Science, National University of Singapore (NUS), Singapore

$\dagger$ Electronic supplementary information (ESI) available. See DOI: 10.1039/c6ra22391e

$\ddagger$ These authors have contributed equally in the manuscript. and enhancement of hydrophilicity in metal oxide systems have been obtained through ultra violet (UV) illumination, ${ }^{5,6}$ visible light, ${ }^{7}$ electro-wetting, ${ }^{8}$ structural modifications, ${ }^{9,10}$ thermal treatment ${ }^{11}$ and laser irradiation. ${ }^{12}$ Detailed studies have been done to understand the underlying mechanism for enhancement in hydrophilicity in transition metal oxides for e.g. $\mathrm{ZnO}$ and $\mathrm{TiO}_{2}$ and the plausible reasons that have been reported for this consequence are removal of organic contaminants, ${ }^{13}$ transition of crystal structure, ${ }^{14}$ increase of surface roughness, ${ }^{15}$ change of surface chemical compositions/hydroxyl content, oxygen vacancies and $\mathrm{Ti}^{3+}$ or $\mathrm{Zn}^{+}$defect sites. ${ }^{16}$ In particular, modifications in wetting through changes in the electronic structure of transition metal oxides due to defect formation have gained attention over the past several years. ${ }^{\mathbf{1 , 3 , 4 1 2 , 1 7}}$ Such modifications have been demonstrated through UV irradiation and photo-induced hydrophilicity has been observed for $\mathrm{TiO}_{2}, \mathrm{SnO}_{2}, \mathrm{ZnO}, \mathrm{WO}_{3}, \mathrm{~V}_{2} \mathrm{O}_{5} \cdot{ }^{18-22}$ The dissociation of water molecules into $\mathrm{H}$ and $\mathrm{OH}$ at vacancies sites of $\mathrm{TiO}_{2}$ have been imaged through non-contact AFM and STM. ${ }^{23-26} \mathrm{SrTiO}_{3}$ whose electronic structure resembles $\mathrm{TiO}_{2}$ does not exhibit photoinduced hydrophilicity under UV light, clearly indicates that wetting properties depend intimately on surface electronic structure, and not solely stoichiometry or surface roughness. ${ }^{27}$

The increase in interactions of water with the surface defect sites have been well documented in the case of $\mathrm{TiO}_{2}$ and $\mathrm{ZnO}$ but the effect of oxygen vacancies on the $4 \mathrm{f}$ element based metal oxides remains largely unexplored except a recent study on $\mathrm{CeO}_{2} \cdot{ }^{28}$ In this article we have studied the wettability of pulsed 
laser deposition (PLD) grown rare-earth $\mathrm{Lu}_{2} \mathrm{O}_{3}$ oxide, with oxygen vacancies and have also investigated the effect of vacancy healing in such systems. In order to understand the underlying mechanism and also to make a comparison, commercially available $\mathrm{SrTiO}_{3}$ substrates were studied by creating oxygen vacancies through thermal annealing. An opposite trend (in terms of how wettability varies with oxygen vacancy) has been observed in the case of these $3 \mathrm{~d}$ and $4 \mathrm{f}$ oxides and this is in accordance with the density functional theory (DFT) calculations performed for such systems.

\section{Experimental and computational methods}

The macro scale contact angle measurements were carried out using the video based fully automated Data Physics optical contact angle microliter dosing system (OCA 40 Micro). Di water drops ( $1 \mu \mathrm{l}$ per drop) with known surface tension $\left(72.80 \mathrm{~N} \mathrm{~m}^{-1}\right)$ were dispensed using Teflon coated motor driven syringe. The contact angles were measured at ambient conditions and a video was recorded (72 frames per second) for every dispensed solvent droplet. Any dynamic changes to the droplet on the surface can be precisely observed through this method. The contact angle was estimated using the sessile drop technique by measuring the angle between the tangent lines along solidliquid interface and liquid-vapour interface of the liquid contour as shown in Fig. 1. A contact angle of $0^{\circ}$ and $180^{\circ}$ correspond to complete wetting and non-wetting respectively. Surfaces exhibiting contact angles below $90^{\circ}$ are called hydrophilic and those above $90^{\circ}$ are called hydrophobic.

The $\mathrm{SrTiO}_{3}$ samples were commercially available high quality single crystal substrates from CrysTec $\mathrm{GmbH}$. The $\mathrm{Lu}_{2} \mathrm{O}_{3}$ thin films were deposited on YSZ [ $\left[\begin{array}{lll}1 & 0 & 0\end{array}\right]$ substrates by pulsed laser deposition using a stoichiometric target of $\mathrm{Lu}_{2} \mathrm{O}_{3}$. YSZ $\left[\begin{array}{lll}1 & 0 & 0\end{array}\right]$ was chosen due to its similar cubic structure of intended $\mathrm{Lu}_{2} \mathrm{O}_{3}\left[\begin{array}{lll}1 & 0 & 0\end{array}\right]$ phase and similar lattice parameter of $5.14 \AA$ whereas $\mathrm{Lu}_{2} \mathrm{O}_{3}[1$ 0 0] also has a lattice parameter of $11.03 \AA . \mathrm{Lu}_{2} \mathrm{O}_{3}$ target was synthesized by a conventional solid state reaction. The starting materials for a target were high purity (99.995\% or higher) powders of $\mathrm{Lu}_{2} \mathrm{O}_{3}$. First, the powders were mixed for several hours manually using mortar and pestle. It was pressed into a 1 in. diameter die by hand press and then further pressed under $120 \mathrm{MPa}$ for $30 \mathrm{~min}$ by cold isostatic pressure. It was then sintered at $1300{ }^{\circ} \mathrm{C}$ inside the tube furnace for $15 \mathrm{~h}$ under the steady flow of oxygen gas. The sintered target were examined by X-ray diffraction using laboratory powder X-ray source.

The thin films were deposited at a temperature of $850^{\circ} \mathrm{C}$ and at 10 mTorr oxygen partial pressure. Before growth chamber

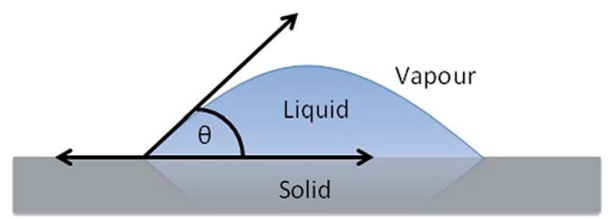

Fig. 1 Schematic diagram of a liquid drop on a solid surface showing contact angle $\theta$. was pumped down to base pressure of $\approx 5 \times 10^{-7}$ mbar. The $248 \mathrm{~nm}$ wavelength $\mathrm{KrF}$ laser was utilized to ablate the ceramic target. The incident laser energy density and the repetition rate were $1.5 \mathrm{~J} \mathrm{~cm}^{-2}$ and $5 \mathrm{~Hz}$, respectively. The crystal structure and phase of the thin films were examined by X-ray diffraction (Bruker D8 Advanced Thin Film XRD).

We employed density functional theory (DFT) calculations to gain insights into the properties of surface oxygen vacancies and their interaction with water. We have included a Hubbard U term on the Lu f states $\left(U_{\text {eff }}=5.4 \mathrm{eV}\right)^{29}$ and Ti d states $\left(U_{\text {eff }}=3.0\right.$ eV). ${ }^{30}$ For $\mathrm{SrTiO}_{3}$, where formally the Ti electronic configuration is $\mathrm{d}^{0}$, we have verified that the reported energetics depend only slightly on the inclusion of the $\mathrm{U}$ term by comparing the results with pure DFT.

We considered the $\mathrm{TiO}_{2}$-terminated (001) surface of $\mathrm{SrTiO}_{3}$ as it is expected to be the exposed surface of commercially available $\mathrm{SrTiO}_{3}$. For $\mathrm{Lu}_{2} \mathrm{O}_{3}$ the [100] orientation of cubic bixbyite is polar, so we can expect some extent of reconstruction to compensate polarity. As a simplified model of a compensated nonpolar surface we have considered the (0001) surface of hexagonal $\mathrm{Lu}_{2} \mathrm{O}_{3}$. The surfaces were represented with slab of 10 and $12 \AA$ thickness for $\mathrm{Lu}_{2} \mathrm{O}_{3}$ and $\mathrm{SrTiO}_{3}$, respectively, where for $\mathrm{SrTiO}_{3}$ we used a symmetric non-stoichiometric slab. The concentration of oxygen vacancies and/or water molecules was set to $1 / 4 \mathrm{ML}$, by using a surface $(2 \times 2)$ unit cell. The water adsorption energy was computed with respect to a water molecule in the gas phase: $E_{\mathrm{ads}}$ $=E\left({ }^{*} \mathrm{H}_{2} \mathrm{O}\right)-E(*)-E\left(\mathrm{H}_{2} \mathrm{O}\right)$, where $E\left({ }^{*} \mathrm{H}_{2} \mathrm{O}\right), E(*)$ and $E\left(\mathrm{H}_{2} \mathrm{O}\right)$ are the total energies of an adsorbed water, the surface, and the gas phase water molecule, respectively. All atomic positions except the bottom oxide layer where fully relaxed until the forces on each atoms were below $0.01 \mathrm{eV} \AA^{-1}$. All calculations were performed within the PBE functional ${ }^{31}$ as implemented in the VASP code. ${ }^{32}$

\section{Results and discussion}

This study mainly reports morphological, structural and wettability behaviours of $\mathrm{SrTiO}_{3}$ and $\mathrm{Lu}_{2} \mathrm{O}_{3}$ sample surfaces before and after annealing.

For $\mathrm{SrTiO}_{3}$, high quality single crystal substrates are bought from Crystec, $\mathrm{GmbH}$, Germany and the as received substrate goes through a 6 hour annealing step at $900{ }^{\circ} \mathrm{C}$ at a very low pressure of $10^{-6}$ Torr. The experiment is performed inside a Pulsed Laser Deposition (PLD) chamber. This annealing step was done to create significant amount of oxygen vacancies in the $\mathrm{SrTiO}_{3}$ single crystal sample.

For $\mathrm{Lu}_{2} \mathrm{O}_{3}$, these REO thin films were grown at low pressure (10 mTorr), so from the beginning they have significant amount of oxygen vacancies in them. In this case the annealing process was significantly different from the previous $\left(\mathrm{SrTiO}_{3}\right)$ one, here pristine $\mathrm{Lu}_{2} \mathrm{O}_{3}$ thin-films were annealed under atmospheric pressure at $900{ }^{\circ} \mathrm{C}$ for 6 hours inside a PLD chamber. Here the annealing process actually reduces oxygen vacancies instead of creating ones.

To rule out trivial (like hydrocarbon desorption) effect of annealing on water contact angle (WCA) we have waited long enough (more than 120 hours) before measuring the wettability data. 
However, before making any comparative study in the field of water contact angle one must make sure that morphological and structural parameters are all similar in the samples before and after annealing procedure. In this direction we have done Atomic Force Microscopy (AFM) and X-ray diffraction (XRD) study for quantification of the morphological and structural parameters, respectively.

In Fig. 2 we have shown the root mean square (rms) surface roughness value of the $\mathrm{Lu}_{2} \mathrm{O}_{3}$ thin-film and $\mathrm{SrTiO}_{3}$ single crystal samples using AFM (Agilent - 5500). Study of surface roughness is very important as it has been shown and well accepted that wettability is characterized by not only the chemical composition but also the roughness of the surface. ${ }^{33}$ To rule out the effect of surface roughness we have shown the surface roughness value of pristine and annealed samples. In case of $\mathrm{Lu}_{2} \mathrm{O}_{3}$ thin-film samples the $R_{\text {rms }}$ values are very similar to each other, varying from $0.22 \mathrm{~nm}$ [Fig. 2(a)] to $0.53 \mathrm{~nm}$ [Fig. 2(b)] before and after annealing respectively. Similarly the surface roughness of $\mathrm{TiO}_{2}$ terminated $\mathrm{SrTiO}_{3}$ single crystal varies from $0.15 \mathrm{~nm}$ [Fig. 2(c)] to $3.01 \mathrm{~nm}$ [Fig. 2(d)] before and after annealing respectively. In $\mathrm{TiO}_{2}$ terminated $\mathrm{SrTiO}_{3}$ single crystal samples AFM images of the pristine samples [Fig. 2(c)] clearly showing the atomic step-edges which is gone after high pressure annealing [Fig. 2(d)]. Value of all this surface roughness is very low, all of them are below $5 \mathrm{~nm}$ for both $\mathrm{SrTiO}_{3}$ single crystal and $\mathrm{Lu}_{2} \mathrm{O}_{3}$ thin-film samples. This (a)

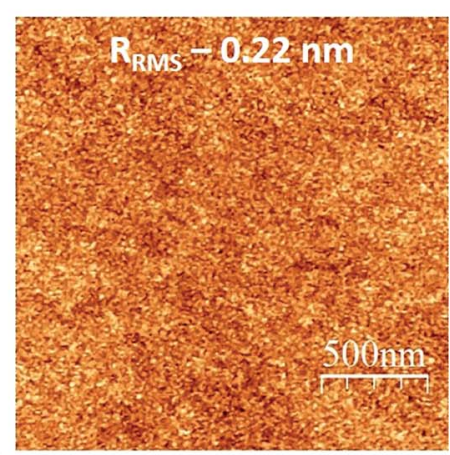

(a)

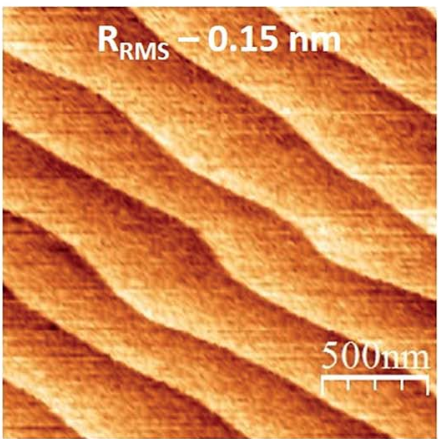

(c)
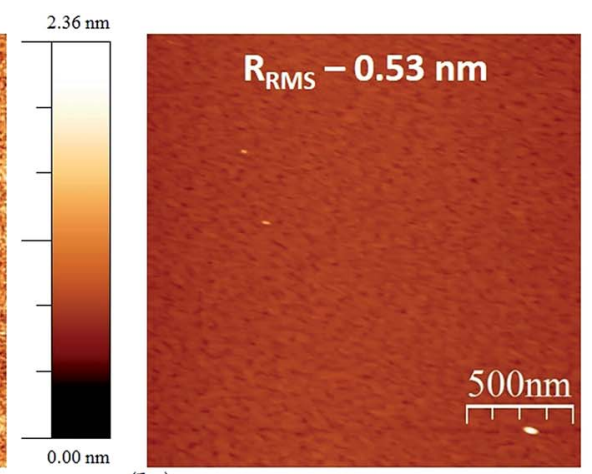

(b)

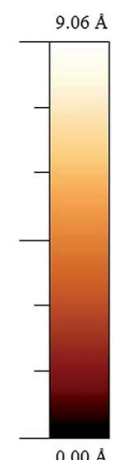

$0.00 \AA$

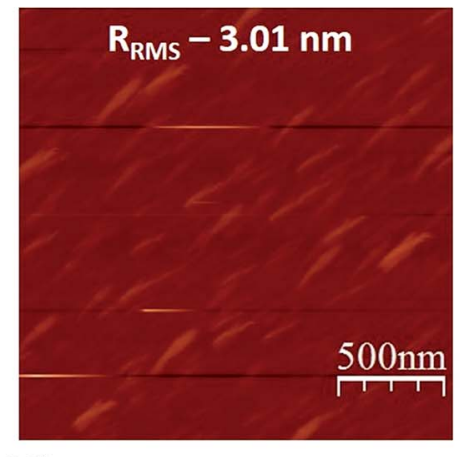

(d)
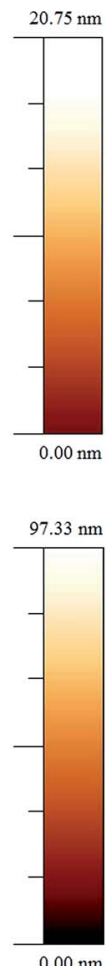

$0.00 \mathrm{~nm}$

Fig. 2 Atomic force microscopy (AFM) images of $\mathrm{Lu}_{2} \mathrm{O}_{3}$ (a) pristine (b) annealed and $\mathrm{TiO}_{2}$ terminated STO (c) pristine (d) annealed.
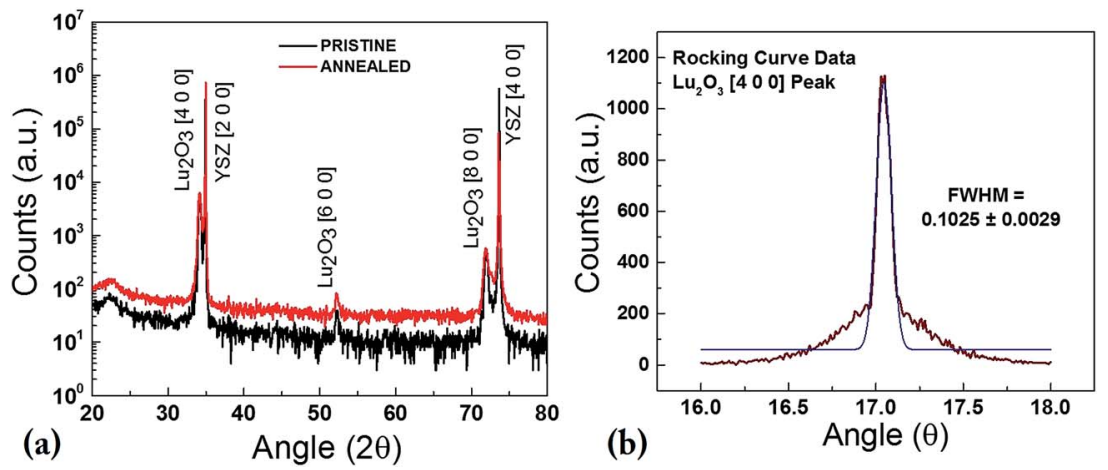

Fig. 3 XRD study - (a) $\theta-2 \theta$ scan of pristine and annealed $\mathrm{Lu}_{2} \mathrm{O}_{3}$ showing no structural change upon annealing; (b) rocking curve measurement of annealed $\mathrm{Lu}_{2} \mathrm{O}_{3}\left[\begin{array}{lll}4 & 0 & 0\end{array}\right]$ peak showing high quality thin-films used in the study. 
amount of morphological change cannot explain the significant change we observe in WCA value.

XRD technique was used to study the effect of annealing on the structural properties of these thin-films and substrates. PLD grown $\mathrm{Lu}_{2} \mathrm{O}_{3}$ thin films were studied using Bruker D8 Advanced Thin Film XRD. Fig. 3(a) shows the theta-2 theta scan of the pristine $\mathrm{Lu}_{2} \mathrm{O}_{3}$ thin-films grown at $800{ }^{\circ} \mathrm{C}$ at 100 mTorr oxygen partial pressure and annealed $\mathrm{Lu}_{2} \mathrm{O}_{3}$ thin-films in red and blue lines respectively. As shown in the images all thin-films are phase pure and $\mathrm{Lu}_{2} \mathrm{O}_{3}$ films grows along $\left[\begin{array}{lll}1 & 0 & 0\end{array}\right]$ direction. First XRD peak for $\mathrm{Lu}_{2} \mathrm{O}_{3}$ is found at $34.1^{\circ}$ for $\left[\begin{array}{lll}4 & 0 & 0\end{array}\right]$ peak and two subsequent peaks of $\mathrm{Lu}_{2} \mathrm{O}_{3}\left[\begin{array}{lll}6 & 0 & 0\end{array}\right]$ and $\left[\begin{array}{lll}8 & 0 & 0\end{array}\right]$ are found at $52.2^{\circ}$ and $71.9^{\circ}$ respectively, along with two substrates peaks of YSZ [2 $\left.\begin{array}{ll}0 & 0\end{array}\right] \&\left[\begin{array}{lll}4 & 0 & 0\end{array}\right]$ at $34.9^{\circ}$ and $73.5^{\circ}$. The careful study at Fig. 3(a) reveals that the XRD pattern and peak location of both pristine and annealed thin-films are identical. The $\mathrm{Lu}_{2} \mathrm{O}_{3}$ thin-films are grown at $800{ }^{\circ} \mathrm{C}$ and it was not expected that annealing at $900{ }^{\circ} \mathrm{C}$ would create any significant structural changes in the highly stable cubic crystal structure of $\mathrm{Lu}_{2} \mathrm{O}_{3}\left[\begin{array}{lll}1 & 0 & 0\end{array}\right]$ phase with lattice parameter of $11.03 \AA$. Additional rocking curve data of annealed $\mathrm{Lu}_{2} \mathrm{O}_{3}\left[\begin{array}{lll}4 & 0 & 0\end{array}\right]$ also suggests very good quality thin-film sample with a FWHM of $0.103^{\circ} \cdot \mathrm{SrTiO}_{3}$ samples were single crystal substrates which eliminates any need of XRD analysis before and after annealing.

Further study was done for the quantification of the oxygen vacancy in the samples, as shown in the Fig. 4 . In case of $\mathrm{Lu}_{2} \mathrm{O}_{3}$ we have used Rutherford Back Scattering (RBS) method to show that relative presence of elemental oxygen increases with the annealing step. For RBS study $\mathrm{Lu}_{2} \mathrm{O}_{3}$ thin-films samples grown on Si ( $\left.\begin{array}{lll}1 & 0 & 0\end{array}\right)$ was used, as it is not possible to find precise determination of oxygen atomic content when substrate is a another oxide like YSZ. The $\mathrm{Lu}_{2} \mathrm{O}_{3}$ thin-films grown on $\mathrm{Si}$ also goes through exactly similar growth and annealing condition like the $\mathrm{Lu}_{2} \mathrm{O}_{3}\left(\begin{array}{lll}1 & 0 & 0\end{array}\right)$ grown on YSZ ( $\left.\begin{array}{lll}1 & 0 & 0\end{array}\right)$. In Fig. 4(a) and (b) as we see elemental analysis using RBS reveals that $\mathrm{Lu}: \mathrm{O}$ ratio is $0.44: 0.56$, whereas after the oxygen annealing the elemental composition ratio of $\mathrm{Lu}: \mathrm{O}$ becomes $0.41: 0.59$, a clear increase of oxygen content and in the latter case the $\mathrm{Lu}$ : $\mathrm{O}$ ratio approaches the ideal elemental ratio of $0.40: 0.60$ in case of $\mathrm{Lu}_{2} \mathrm{O}_{3}$. RBS technique is clearly showing all the silicon, oxygen and lutetium edges in the spectra. [Further support of enhanced presence of relative oxygen can be achieved using XPS data

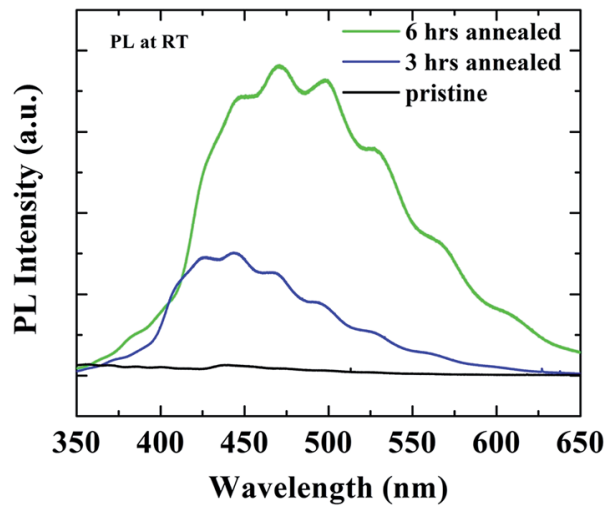

Fig. 5 Photoluminescence of as-received and annealed $\mathrm{SrTiO}_{3}$ single crystal substrate.

which shows clear increment of the $\mathrm{O} 1 \mathrm{~s}$ to $\mathrm{Lu} 4 \mathrm{~d}$ ratio $(\mathrm{O} 1 \mathrm{~s}: \mathrm{Lu}$ 4d) with annealing, a result consistent with reduction of oxygen vacancies (see 'ESI' Fig. S1 $\dagger$ ).]

In the $\mathrm{SrTiO}_{3}$ case RBS technique could not be used to assess oxygen vacancy content as for oxides with more than two elements it is difficult to decisively find out elemental composition at a very precise level, particularly when one element is low atomic number (oxygen) with very low Rutherford crosssection. As we have discussed above, the low oxygen partial pressure annealing should enhance amount of oxygen vacancies. To further detect the effect of annealing in the $\mathrm{SrTiO}_{3}$ substrates photoluminescence (PL) was performed after annealing at room temperature. Fig. 5 shows that the intensity of the broad PL peak (position around $475 \mathrm{~nm}$ ) of $\mathrm{SrTiO}_{3}$ substrate increases monotonically with increasing annealing time. It has been previously reported that broad PL emission of $\mathrm{SrTiO}_{3}$ in blue range (between 450 to $500 \mathrm{~nm}$ ) dramatically increase with increasing oxygen vacancy in the $\mathrm{SrTiO}_{3} \cdot{ }^{34-37}$ It has been theorized that oxygen vacancies in $\mathrm{SrTiO}_{3}$ generate conduction carriers and stabilize a hole level in a self-trapped state and hence the doped conduction electrons and the ingap state produce a radiative process that results in blue-light emission. ${ }^{34}$ Also here in Fig. 5 we find a similar trend which clearly indicates that with increasing annealing time more oxygen vacancies are created in our $\mathrm{SrTiO}_{3}$ substrates.
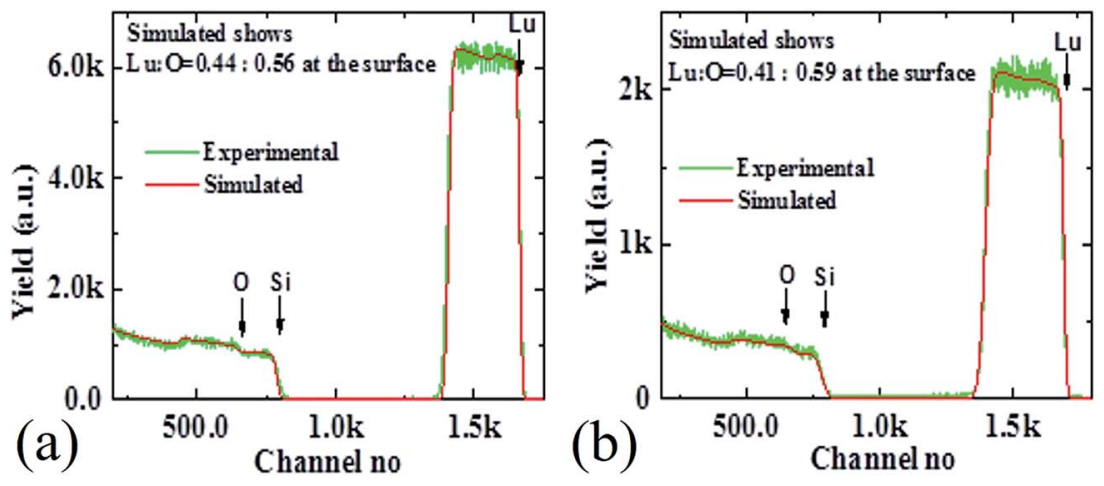

Fig. 4 Quantification of oxygen vacancy using RBS technique in (a) as-grown and (b) annealed $\mathrm{Lu}_{2} \mathrm{O}_{3}$ sample. 
(a)

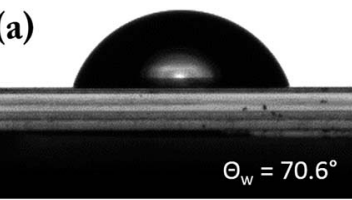

(c)

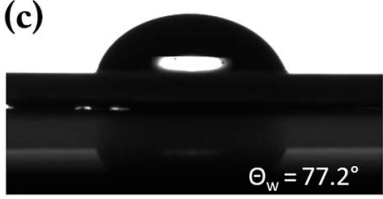

(b)

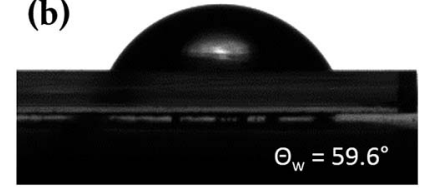

(d)

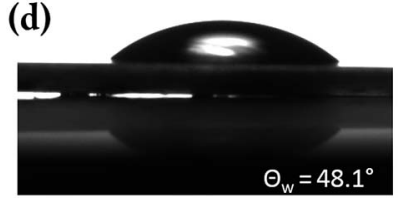

Fig. 6 Water contact angle obtained on $\mathrm{Lu}_{2} \mathrm{O}_{3}(\mathrm{a})$ pristine (b) annealed and $\mathrm{SrTiO}_{3}$ (c) pristine (d) annealed.

Fig. 6 shows the contact angle measurement of $\mathrm{Lu}_{2} \mathrm{O}_{3}$ thinfilms and $\mathrm{SrTiO}_{3}$ single crystal before and after annealing. As shown in Fig. 6(a) the as-grown $\mathrm{Lu}_{2} \mathrm{O}_{3}$ thin-films sample showing a moderately high water contact angle $\left(70.6^{\circ}\right)$ before any annealing process, whereas following the annealing [Fig. 6(c)] water contact angle comes out to be much lower $\left(59.6^{\circ}\right)$. XPS spectra collected in the $\mathrm{C} 1 \mathrm{~s}$ region (Fig. S2 $\dagger$ ) show no significant change upon annealing, suggesting that the change in contact angle is not due to the formation (or removal) of surface carbonates. A very similar behaviour of WCA upon annealing is also found on another REO thin-film system of $\mathrm{CeO}_{2}$ [see 'ESI' Fig. S3 for the detailst].

Subsequently in the lower panel of the Fig. 6, i.e. in Fig. 6(c) and (d) we have reported the water contact angle of as-received and annealed $\mathrm{SrTiO}_{3}$ single crystal samples respectively. The

pristine $\mathrm{SrTiO}_{3}$ single crystal samples shows high water contact angle $\left(77.2^{\circ}\right)$ compared to the annealed thin-films $\left(48.1^{\circ}\right)$.

Here we find an interesting contradictory behaviour in REO $\mathrm{Lu}_{2} \mathrm{O}_{3}$ (and $\mathrm{CeO}_{2}$ ) thin film and $\mathrm{SrTiO}_{3}$ single crystal samples: for $\mathrm{SrTiO}_{3}$, oxygen vacancy promotes wettability, while for $\mathrm{Lu}_{2} \mathrm{O}_{3}$ (and $\mathrm{CeO}_{2}$ ) it is the opposite direction - oxygen vacancy hinders wettability.

Finally to understand the contradictory behaviour of water contact angle with the creation of oxygen vacancies in $\mathrm{SrTiO}_{3}$ and $\mathrm{Lu}_{2} \mathrm{O}_{3}$ systems, we have used Density Functional Theory (DFT) calculations. Various configurations have been considered for the adsorption of water on the oxide surface in presence of an oxygen vacancy. In the case of the $\mathrm{TiO}_{2}$-terminated $\mathrm{SrTiO}_{3}(001)$ surface we found that in the most stable configuration water adsorbs dissociatively at the vacancy site with an adsorption energy of $-2.30 \mathrm{eV}$, to be compared to -0.74 and $-0.98 \mathrm{eV}$ of molecular and dissociative adsorption on the clean surface. In the dissociated configuration the oxygen of water heals the vacancy and the two hydrogen atoms form hydroxyl groups with surface oxygen atoms, Fig. 7(d). A similar mechanism has been already reported for $\mathrm{TiO}_{2}$ and other oxides as discussed in the introduction. The polar hydroxyls groups created upon contact of the defective surface with water can form oxygen bonds with the subsequent water layers increasing the surface wettability. ${ }^{38}$ Conversely, on the hexagonal $\mathrm{Lu}_{2} \mathrm{O}_{3}$ surface healing of oxygen vacancies with water is not energetically favourable and the most stable configuration consists of molecular water adsorbed on a Lu site adjacent to the vacancy (Fig. 6(b)), resulting in an adsorption energy of $-0.74 \mathrm{eV}$ (compared to $-0.37 \mathrm{eV}$ of the clean surface). This adsorption mode
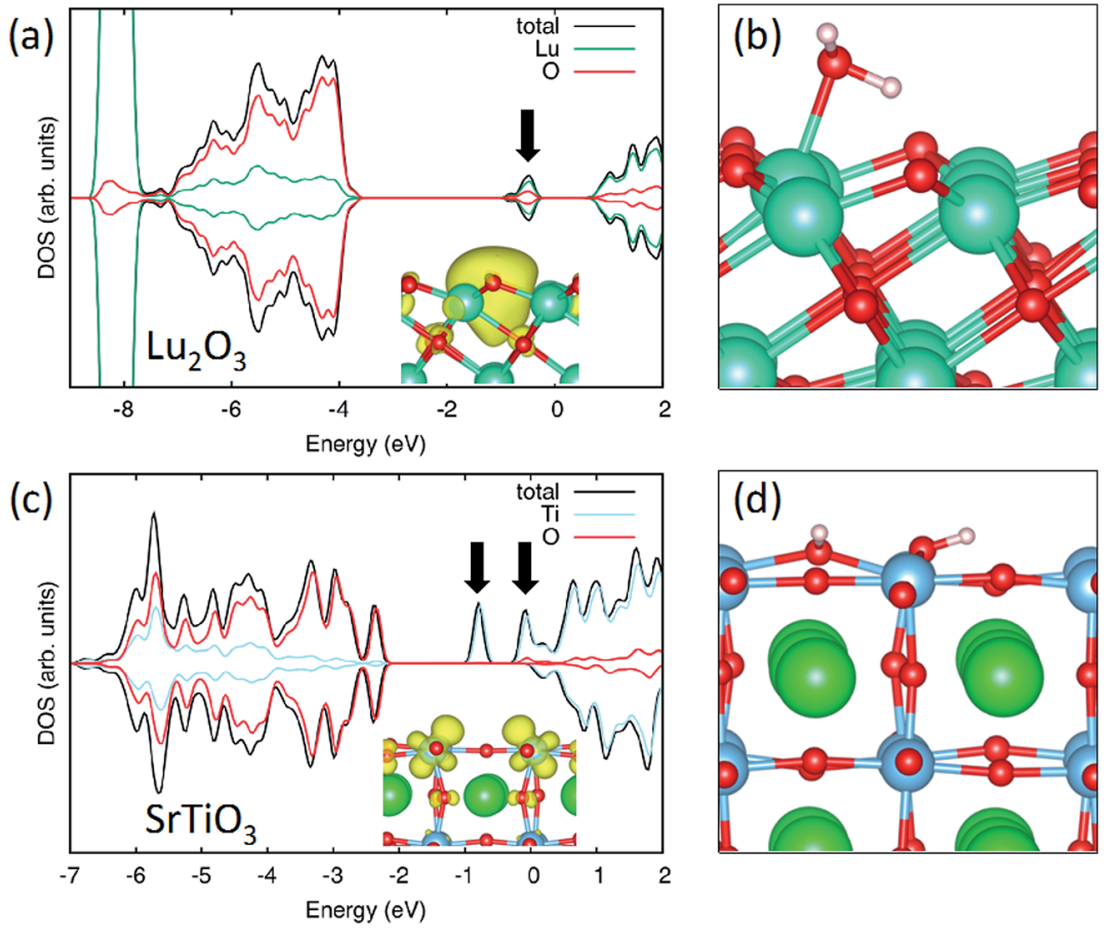

Fig. 7 Density of States (DOS) for a surface oxygen vacancy at the $\mathrm{Lu}_{2} \mathrm{O}_{3}$ (a) and $\mathrm{SrTiO}_{3}$ (c). The insets show the electron density of the defect state, indicated by the arrows in the DOS. Most stable configurations for a water molecule at the surface of defective $\mathrm{Lu}_{2} \mathrm{O}_{3}(\mathrm{~b})$ and $\mathrm{SrTiO}_{3}(\mathrm{~d}) . \mathrm{O}$ atoms are represented in red, Lu in light green, $\mathrm{Sr}$ in green, $\mathrm{Ti}$ in blue and $\mathrm{H}$ in white. 
does not create hydroxyls groups and thus does not enhance surface wetting in agreement with the contact angle measurements. The increased wetting observed experimentally for the pristine sample, Fig. 5, can be ascribed to $\mathrm{OH}$ species present on this sample, likely at low coordinated sites, which desorbs (being oxidized to leave a filled, unprotonated oxygen site only, desorbing as water) upon annealing. This interpretation is consistent with $\mathrm{O}$ 1s data, Fig. S1, $\dagger$ which show a higher $\mathrm{OH}$ signal for the pristine sample.

The difference between the two materials can be linked to the different nature of the oxygen vacancy on the two oxides. In the case of $\mathrm{SrTiO}_{3}$ the vacancy formation reduces the Ti ions from +4 to +3 oxidation state (with a concentration of two $\mathrm{Ti}^{3+}$ per vacancy site), Fig. 7(c). When water is adsorbed the two extra-electrons remain in the Ti $3 \mathrm{~d}$ states and the concentration of $\mathrm{Ti}^{3+}$ is maintained. This similarity between the electronic properties of O-deficient and hydroxylated surface has been already observed for $\mathrm{TiO}_{2} \cdot{ }^{39}$

In the case of $\mathrm{Lu}_{2} \mathrm{O}_{3}$, the $\mathrm{Lu} \mathrm{f}$ states are not accessible for reduction and the two electrons left in the material when a neutral oxygen vacancy is formed stay localized at the vacancy site Fig. 7(a). This state corresponds to a defect state in the band gap. When water is introduced, the adsorption at the vacancy site is hindered as the extra electrons cannot be accommodated at the metal sites (as the Lu states are too high in energy). As a consequence, the molecule stays at a metal site near the vacancy where it can benefit from electrostatic interaction with the trapped electrons.

We also note a correlation between the increased wetting at defective $\mathrm{SrTiO}_{3}$ which is more conductive, compared to $\mathrm{Lu}_{2} \mathrm{O}_{3}$ which maintains its insulating nature.

\section{Conclusion}

In this article, we have reported the contradictory behaviour of water contact angle with oxygen defect creation in $3 \mathrm{~d}$ transition metal based oxide $\mathrm{SrTiO}_{3}$ and $4 \mathrm{f}$ rare-earth based $\mathrm{Lu}_{2} \mathrm{O}_{3}$ systems. In case of $\mathrm{SrTiO}_{3}$ we find that oxygen vacancy promotes wettability, where as in case of $\mathrm{Lu}_{2} \mathrm{O}_{3}$ we find the effect of oxygen is exactly opposite, i.e. that oxygen vacancy inhibits wettability. Post growth annealing at either high or low oxygen partial pressure was used to remove or create oxygen vacancy in both $\mathrm{Lu}_{2} \mathrm{O}_{3}$ and $\mathrm{SrTiO}_{3}$ samples respectively. We have used XRD and AFM measurement to rule out any possible role of structural and surface morphological change (with annealing) that can affect water contact angle. Further study was done using RBS and room temperature PL technique to demonstrate the change of oxygen vacancy level before and after annealing. Finally DFT calculations was used to conclude that in the case of $\mathrm{SrTiO}_{3-x}$ we expect an increase of hydroxylation compared to stoichiometric $\mathrm{SrTiO}_{3}$ with a consequent increase of wettability, which effect is not present for $\mathrm{Lu}_{2} \mathrm{O}_{3}$.

\section{Author contributions}

The manuscript was written through contributions of all authors. All authors have given approval to the final version of the manuscript.

\section{Funding sources}

M. Annamalai would like to acknowledge support from NUSNNI core fund. T. Venkatesan would like to acknowledge the funding support from NRF CRP (NRF-CRP8-2011-06). The theoretical simulations where performed at the National Energy Research Scientific Computing Center, a DOE Office of Science User Facility supported by the Office of Science of the U.S. Department of Energy under Contract No. DE-AC02-05CH11231.

\section{Acknowledgements}

This research used resources of the National Energy Research Scientific Computing Center, a DOE Office of Science User Facility supported by the Office of Science of the U.S. Department of Energy under Contract No. DE-AC02-05CH11231.

\section{References}

1 K. Liu, M. Cao, A. Fujishima and L. Jiang, Bio-Inspired Titanium Dioxide Materials with Special Wettability and Their Applications, Chem. Rev., 2014, 114(19), 10044-10094.

2 S. N. Das, J. H. Choi, J. P. Kar and J. M. Myoung, Tunable and reversible surface wettability transition of vertically aligned ZnO nanorod arrays, Appl. Surf. Sci., 2009, 255(16), 7319-7322.

3 V. Khranovskyy, T. Ekblad, R. Yakimova and L. Hultman, Surface morphology effects on the light-controlled wettability of ZnO nanostructures, Appl. Surf. Sci., 2012, 258(20), 8146-8152.

4 E. L. Papadopoulou, M. Barberoglou, V. Zorba, A. Manousaki, A. Pagkozidis, E. Stratakis and C. Fotakis, Reversible Photoinduced Wettability Transition of Hierarchical ZnO Structures, J. Phys. Chem. C, 2009, 113(7), 2891-2895.

5 R.-D. Sun, A. Nakajima, A. Fujishima, T. Watanabe and K. Hashimoto, Photoinduced Surface Wettability Conversion of $\mathrm{ZnO}$ and $\mathrm{TiO}_{2}$ Thin Films, J. Phys. Chem. B, 2001, 105(10), 1984-1990.

6 R. Wang, K. Hashimoto, A. Fujishima, M. Chikuni, E. Kojima, A. Kitamura, M. Shimohigoshi and T. Watanabe, Light-induced amphiphilic surfaces, Nature, 1997, 388(6641), 431-432.

7 H. Irie, S. Washizuka, N. Yoshino and K. Hashimoto, Visiblelight induced hydrophilicity on nitrogen-substituted titanium dioxide films, Chem. Commun., 2003, (11), 1298-1299.

$8 \mathrm{M}$. Frieder and B. Jean-Christophe, Electrowetting: from basics to applications, J. Phys.: Condens. Matter, 2005, $17(28)$, R705.

9 D. Quéré, Wetting and Roughness, Annu. Rev. Mater. Res., 2008, 38(1), 71-99.

10 V. Zorba, X. Chen and S. S. Mao, Superhydrophilic $\mathrm{TiO}_{2}$ surface without photocatalytic activation, Appl. Phys. Lett., 2010, 96(9), 093702.

11 G. Lu, A. Linsebigler and J. T. Yates, $\mathrm{Ti}^{3+}$ Defect Sites on $\mathrm{TiO}_{2}$ (110): Production and Chemical Detection of Active Sites, $J$. Phys. Chem., 1994, 98(45), 11733-11738.

12 M. R. Bayati, S. Joshi, R. Molaei, R. J. Narayan and J. Narayan, Ultrafast switching in wetting properties of $\mathrm{TiO}_{2} / \mathrm{YSZ} / \mathrm{Si}(001)$ 
epitaxial heterostructures induced by laser irradiation, $J$. Appl. Phys., 2013, 113(6), 063706.

13 T. Shibata, H. Irie, M. Ohmori, A. Nakajima, T. Watanabe and K. Hashimoto, Comparison of photochemical properties of brookite and anatase $\mathrm{TiO}_{2}$ films, Phys. Chem. Chem. Phys., 2004, 6(6), 1359-1362.

14 T. Neuheuser, B. A. Hess, C. Reutel and E. Weber, Ab Initio Calculations of Supramolecular Recognition Modes. Cyclic versus Noncyclic Hydrogen Bonding in the Formic Acid/ Formamide System, J. Phys. Chem., 1994, 98(26), 6459-6467.

15 J. J. Park, D. Y. Kim, S. S. Latthe, J. G. Lee, M. T. Swihart and S. S. Yoon, Thermally induced superhydrophilicity in $\mathrm{TiO}_{2}$ films prepared by supersonic aerosol deposition, ACS Appl. Mater. Interfaces, 2013, 5(13), 6155-6160.

16 Y. C. Lee, Y. P. Hong, H. Y. Lee, H. Kim, Y. J. Jung, K. H. Ko, H. S. Jung and K. S. Hong, Photocatalysis and hydrophilicity of doped $\mathrm{TiO}_{2}$ thin films, J. Colloid Interface Sci., 2003, 267(1), 127-131.

17 H. Hu, H.-F. Ji and Y. Sun, The effect of oxygen vacancies on water wettability of a ZnO surface, Phys. Chem. Chem. Phys., 2013, 15(39), 16557-16565.

18 X. Feng, J. Zhai and L. Jiang, The Fabrication and Switchable Superhydrophobicity of $\mathrm{TiO}_{2}$ Nanorod Films, Angew. Chem., Int. Ed., 2005, 44(32), 5115-5118.

19 W. Zhu, X. Feng, L. Feng and L. Jiang, UV-manipulated wettability between superhydrophobicity and superhydrophilicity on a transparent and conductive $\mathrm{SnO}_{2}$ nanorod film, Chem. Commun., 2006, (26), 2753-2755.

20 S. Wang, X. Feng, J. Yao and L. Jiang, Controlling Wettability and Photochromism in a Dual-Responsive Tungsten Oxide Film, Angew. Chem., Int. Ed., 2006, 45(8), 1264-1267.

21 X. Feng, L. Feng, M. Jin, J. Zhai, L. Jiang and D. Zhu, Reversible Super-hydrophobicity to Super-hydrophilicity Transition of Aligned ZnO Nanorod Films, J. Am. Chem. Soc., 2004, 126(1), 62-63.

22 H. S. Lim, D. Kwak, D. Y. Lee, S. G. Lee and K. Cho, UV-Driven Reversible Switching of a Roselike Vanadium Oxide Film between Superhydrophobicity and Superhydrophilicity, $J$. Am. Chem. Soc., 2007, 129(14), 4128-4129.

23 C. L. Pang, A. Sasahara, H. Onishi, Q. Chen and G. Thornton, Noncontact atomic force microscopy imaging of water dissociation products on $\mathrm{TiO}_{2}$ (110), Phys. Rev. B, 2006, 74(7), 073411.

24 S. Wendt, J. Matthiesen, R. Schaub, E. K. Vestergaard, E. Lægsgaard, F. Besenbacher and B. Hammer, Formation and Splitting of Paired Hydroxyl Groups on Reduced $\mathrm{TiO}_{2}$ (110), Phys. Rev. Lett., 2006, 96(6), 066107.

25 S. Wendt, R. Schaub, J. Matthiesen, E. K. Vestergaard, E. Wahlström, M. D. Rasmussen, P. Thostrup, L. M. Molina, E. Lægsgaard, I. Stensgaard, B. Hammer and F. Besenbacher, Oxygen vacancies on $\mathrm{TiO}_{2}\left(\begin{array}{lll}1 & 1 & 0\end{array}\right)$ and their interaction with $\mathrm{H}_{2} \mathrm{O}$ and $\mathrm{O}_{2}$ : A combined high-resolution STM and DFT study, Surf. Sci., 2005, 598(1-3), 226-245.

26 O. Bikondoa, C. L. Pang, R. Ithnin, C. A. Muryn, H. Onishi and G. Thornton, Direct visualization of defect-mediated dissociation of water on $\mathrm{TiO}_{2}$ (110), Nat. Mater., 2006, 5(3), 189-192.

27 M. Miyauchi, A. Nakajima, A. Fujishima, K. Hashimoto and T. Watanabe, Photoinduced Surface Reactions on $\mathrm{TiO}_{2}$ and $\mathrm{SrTiO}_{3}$ Films: Photocatalytic Oxidation and Photoinduced Hydrophilicity, Chem. Mater., 2000, 12(1), 3-5.

28 S. Khan, G. Azimi, B. Yildiz and K. K. Varanasi, Role of surface oxygen-to-metal ratio on the wettability of rareearth oxides, Appl. Phys. Lett., 2015, 106(6), 061601.

29 H. Jiang, R. I. Gomez-Abal, P. Rinke and M. Scheffler, Localized and Itinerant States in Lanthanide Oxides United by GW@LDA+U, Phys. Rev. Lett., 2009, 102(12), 126403.

30 E. Finazzi, C. Di Valentin, G. Pacchioni and A. Selloni, Excess electron states in reduced bulk anatase $\mathrm{TiO}_{2}$ : comparison of standard GGA, GGA+U, and hybrid DFT calculations, $J$. Chem. Phys., 2008, 129(15), 154113.

31 J. P. Perdew, J. A. Chevary, S. H. Vosko, K. A. Jackson, M. R. Pederson, D. J. Singh and C. Fiolhais, Atoms, molecules, solids, and surfaces: applications of the generalized gradient approximation for exchange and correlation, Phys. Rev. B: Condens. Matter Mater. Phys., 1992, 46(11), 6671-6687.

32 G. Kresse and J. Furthmüller, Efficient iterative schemes for ab initio total-energy calculations using a plane-wave basis set, Phys. Rev. B, 1996, 54(16), 11169-11186.

33 R. N. Wenzel, Surface Roughness and Contact Angle, J. Phys. Colloid Chem., 1949, 53(9), 1466-1467.

34 D. Kan, T. Terashima, R. Kanda, A. Masuno, K. Tanaka, S. Chu, H. Kan, A. Ishizumi, Y. Kanemitsu, Y. Shimakawa and M. Takano, Blue-light emission at room temperature from $\mathrm{Ar}^{+}$-irradiated $\mathrm{SrTiO}_{3}$, Nat. Mater., 2005, 4(11), 816-819.

35 Z. Q. Liu, C. J. Li, W. M. Lü, X. H. Huang, Z. Huang, S. W. Zeng, X. P. Qiu, L. S. Huang, A. Annadi, J. S. Chen, J. M. D. Coey and T. Venkatesan, Ariando, Origin of the Two-Dimensional Electron Gas at $\mathrm{LaAlO}_{3} / \mathrm{SrTiO}_{3}$ Interfaces: The Role of Oxygen Vacancies and Electronic Reconstruction, Phys. Rev. X, 2013, 3(2), 021010.

36 Z. Q. Liu, D. P. Leusink, X. Wang, W. M. Lü, K. Gopinadhan, A. Annadi, Y. L. Zhao, X. H. Huang, S. W. Zeng, Z. Huang, A. Srivastava, S. Dhar and T. Venkatesan, Ariando, MetalInsulator Transition in $\mathrm{SrTiO}_{3-x}$ Thin Films Induced by Frozen-Out Carriers, Phys. Rev. Lett., 2011, 107(14), 146802.

37 A. Kalabukhov, R. Gunnarsson, J. Börjesson, E. Olsson, T. Claeson and D. Winkler, Effect of oxygen vacancies in the $\mathrm{SrTiO}_{3}$ substrate on the electrical properties of the $\mathrm{LaAlO}_{3} / \mathrm{SrTiO}_{3}$ interface, Phys. Rev. B: Condens. Matter Mater. Phys., 2007, 75(12), 121404.

38 N. Giovambattista, P. G. Debenedetti and P. J. Rossky, Effect of Surface Polarity on Water Contact Angle and Interfacial Hydration Structure, J. Phys. Chem. B, 2007, 111(32), 9581-9587.

39 C. Di Valentin, G. Pacchioni and A. Selloni, Electronic Structure of Defect States in Hydroxylated and Reduced Rutile $\mathrm{TiO}_{2}$ (110) Surfaces, Phys. Rev. Lett., 2006, 97(16), 166803. 